\title{
Survival and prediction of successful ventilator weaning in COPD patients requiring mechanical ventilation for more than 21 days
}

\author{
S. Nava*, F. Rubini*, E. Zanotti*, N. Ambrosino*, C. Bruschi, \\ M. Vitacca+, C. Fracchia*, C. Rampulla*
}

Survival and prediction of successful ventilator weaning in COPD patients requiring mechanical ventilation for more than 21 days. S. Nava, F. Rubini, E. Zanotti, N. Ambrosino, C. Bruschi, M. Vitacca, C. Fracchia, C. Rampulla. CERS Journals Ltd 1994.

ABSTRACT: We studied survival and failure or success of weaning from mechanical ventilation (MV) in 42 consecutive chronic obstructive pulmonary disease (COPD) patients requiring prolonged MV (more than 21 days) after an episode of acute respiratory failure requiring admission to our Intermediate Intensive Care Unit (IICU).

Parameters including arterial blood gases, pulmonary function tests, respiratory muscle force, neuromuscular drive, and nutritional status were recorded during a phase of clinical stability, in order to identify the features related to survival and weaning. All the patients were submitted to a comprehensive rehabilitation programme. Successful weaning from MV was defined as complete respiratory autonomy for at least $48 \mathrm{~h}$.

Twenty three patients were successfully weaned from MV after an average period of 44 days (Group A), requiring no further MV during their stay in hospital, whilst the remaining 19 patients were not able to be disconnected from the ventilator (Group B). The discriminant analysis showed that weaning from MV was significantly associated with arterial carbon dioxide tension $\left(\mathrm{PaCO}_{2}\right)$, neuromuscular drive $\left(\mathrm{P}_{0.1}\right)$, maximal inspiratory pressure (MIP), arterial oxygen tension $\left(\mathrm{PaO}_{2}\right)$, the ratio of respiratory frequency to tidal volume $\left(f / V_{T}\right)$ and the serum protein level. Other pulmonary function tests (forced expiratory volume in one second $\left(F_{E V}\right), F E V_{1} /$ forced $_{1}$ vital capacity (FVC), anthropometric data, nutritional status, number of pulmonary exacerbations during MV and evidence of cor pulmonale, were similar in the two groups. The discriminant equation considering $\mathrm{PaCO}_{2}$ and MIP could separate the two groups with an accuracy of $84 \%$. The overall survival at 2 yrs was $40 \%$; in Group B it was significantly lower than in Group A (22 vs 68\%). Most of the deaths occurred within the first 120 days after intubation. None of the parameters considered could significantly predict the survival rate.

We conclude that more than half of COPD patients requiring prolonged MV (more than 21 days) could be successfully weaned. A simple equation including $\mathrm{PaCO}_{2}$ and MIP could correctly identify the weaning success or failure in about $84 \%$ of patients. The survival rate at 2 yrs is poor in those who could not be weaned, but is not associated with any of the indices considered.

Eur Respir J., 1994, 7, 1645-1652.
*Division of Pneumology, Centro Medico di Riabilitazione di Montescano, Montescano, Italy. +Division of Pneumology, Centro Medico di Riabilitazione di Gussago, Fondazione Clinica del Lavoro IRCCS, Italy.

Correspondence: S. Nava

Division of Pneumology

Centro Medico di Montescano

27040 Montescano (PV)

Italia

Keywords:

Chronic obstructive pulmonary disease mechanical ventilation

predictive parameters

survival

weaning

Received: October 271993

Accepted after revision June 121994
Patients affected by chronic obstructive pulmonary diseases (COPD) undergo recurrent episodes of acute exacerbation of their disease, often requiring mechanical ventilation (MV) [1]. The immediate recovery rate varies from about $60 \%$ to more than $90 \%$, [2-9], whilst the survival after $1 \mathrm{yr}$ (table 1 ) is quite low $[2,3,6$, 9-11]. There is a subset of COPD patients in which the weaning from MV is particularly difficult $[12,13]$. This may be related to the fact that these patients are in the terminal phase of their chronic disease and their respiratory function and mechanics are severely compromised.
Respiratory muscle weakness, hypercapnia, hypoxia, malnutrition and the increasing number of acute exacerbations may also lead to difficulties in the weaning process from MV [1, 14]. Almost all of these patients have had to undergo tracheotomy, when the need for respiratory assistance is prolonged in excess of 2-4 weeks [15].

Very few studies [2-4], mainly carried out in North America, have investigated the outcome and long-term survival of this particular group of patients. Despite the efforts made by these authors, it is apparent that premorbid measurements or clinical parameters recorded during the 
Table 1. - Survival rates at one year, obtained in different studies, in COPD patients who underwent mechanical ventilation

\begin{tabular}{lrrc}
$\begin{array}{l}\text { First } \\
\text { author }\end{array}$ & Year & [Ref.] & $\begin{array}{c}\text { Survival at } 1 \mathrm{yr} \\
\%\end{array}$ \\
\hline MENZIES & 1989 & {$[2]$} & 34 \\
KAELIN & 1987 & {$[3]$} & 41 \\
GILLESPIE & 1986 & {$[9]$} & 49 \\
PETHERAM & 1980 & {$[6]$} & 36 \\
JESSEN & 1967 & {$[11]$} & 47 \\
BRADLEY & 1964 & {$[10]$} & 37 \\
\hline
\end{tabular}

COPD: chronic obstructive pulmonary disease.

acute phase of illness are not always predictive of the outcome and survival of COPD patients requiring MV. This is because these measurements are either not always available, the clinical status of the patient at the time of the measurement is uncertain, and the effects of the acute illness (i.e. fever, hyperleucocytosis, plasma protein levels, etc.) may unduly influence these parameters.

The objectives of the present study were: 1) to describe the outcome and long-term survival of COPD patients ventilated for more than 21 days; and 2) to identify simple parameters, recorded in a phase of clinical stability, which would be useful to predict whether or not these patients will eventually be disconnected from the ventilator.

\section{Materials and methods}

We studied 42 consecutive COPD patients, mechanicallyventilated for 21 or more days from January 1990 to May 1992, at the Intermediate Intensive Care Unit (IICU) of Montescano Rehabilitation Centre in Italy. The study design was prospective. The American Thoracic Society (ATS) criteria were used to define COPD [16]. Patients with concomitant neurological diseases, other respiratory diseases, congestive heart failure, cancer and other systemic disease, were excluded from the study. The patients had been intubated in one of the five ICUs connected with our Rehabilitation Centre and transferred to our Department, after tracheostomy had been performed, if weaning from MV was proving difficult to achieve. A difficult weaning was defined when the patients had at least two unsuccessful T-piece trials. The time elapsed from intubation to tracheostomy varied between 7 and 20 days, whilst the time from the beginning of MV to admission to our IICU ranged from 8-28 days. Criteria for institution of MV had been standardized for the five ICUs prior to the beginning of the study, and consisted of: rapid deterioration in neurological status (Glasgow Coma Scale $<9$ ); acute onset of severe hypercapnia (arterial carbon dioxide tension $\left.\left(\mathrm{PaCO}_{2}\right)>9.3 \mathrm{kPa}\right)$, acute decrease in $\mathrm{pH}(<7.3)$, tachypnoea and/or abdominal paradox.

In most of these patients a noninvasive approach with nasal positive pressure ventilation had been unsuccessful, making endotracheal intubation unavoidable. All the patients were ventilated using conventional respirators (Bird 6400 ST, Palm Springs, USA; Cesar, Taema, France; Amadeus or Veolar, Hamilton Medical, Rhazuns Switzerland; and Servo 900 B or C, Siemens, Sweden) in the $\mathrm{A} / \mathrm{C}$ mode. The weaning trials were performed switching the ventilator to the pressure support ventilation (PSV) mode, with a peak inspiratory pressure (PIP) (mean \pm SD $16 \pm 4 \mathrm{cmH}_{2} \mathrm{O}$ ) able to maintain a good expiratory tidal volume (VT) (about $8-10 \mathrm{ml} \cdot \mathrm{kg}^{-1}$ ), and with a fractional inspiratory oxygen $\left(\mathrm{FIO}_{2}\right)$ able to maintain the arterial oxygen saturation $\left(\mathrm{SaO}_{2}\right)>93 \%$. In most of the patients (33 patients) an external positive end-expiratory pressure (PEEP) was also applied (mean \pm sD $3.2 \pm 2.1 \mathrm{cmH}_{2} \mathrm{O}$ ). The hours of ventilation in $\mathrm{A} / \mathrm{C}$ mode with respect to the time in PSV mode were gradually reduced. If the patients were able to maintain an $\mathrm{SaO}_{2}>93 \%$, changing the level of $\mathrm{PaCO}_{2}$ less than $5 \%$, during PSV mode for $24 \mathrm{~h}$, the PIP was progressively reduced until ventilation was suspended. Weaning success was defined as complete autonomy from the ventilator for at least $48 \mathrm{~h}$, with oxygen saturation (breathing room air or $\mathrm{O}_{2}$ ) above $90 \%$, and absence of any fatiguing pattern of breathing (tachypnoea, marked use of neck inspiratory muscle, and asynchronous or paradoxical movements of chest wall and abdomen), as defined by Rochester [17]. None of the patients who were successfully weaned required further MV during the remainder of their stay in the IICU. Weaning failure was defined as death whilst on MV or failure to be disconnected from the respirator after 4 months.

Patients were, therefore, divided into two separate groups for data analysis, those weaned from MV (Group A), and those not weaned (Group B). Comprehensive treatment included standard medical therapy for COPD and related complications $\left(\right.$ beta $_{2}$-agonists, xanthines and antibiotics), nutritional support and rehabilitative programmes. Nutritional therapy was standardized with a lipid prevalence and intravenous albumin when needed, and was prescribed by the Nutritional Service of our Institution. The rehabilitation programme consisted of a standardized programme of leg and arm mobilization, chest physiotherapy, counselling and postural drainage when needed. Respiratory muscle training was also performed using inspiratory resistances, as described by ALDRICH and UhrLASS [18], and in four patients training in swallowing was also needed.

All the variables included in data analysis were recorded a few days after IICU admission (from 5-10 days), whilst the patients were still ventilated but in a phase of clinical stability. Clinical stability was defined as: 1) absence of hyperthermia; 2) stable haemodynamics (mean arterial blood pressure not varying by more than $10 \mathrm{mmHg}$ in the preceeding 3 days); 3) patient conscious and cooperative; 4) no administration of respiratory depressant drugs; and 5) stability in arterial blood gases under MV (not varying by more than $5 \%$ in the preceeding 3 days).

The following measurements were recorded in the phase of clinical stability described:

Anthropometric data. These included age, sex, height and weight. 
Arterial blood gases. $\mathrm{pH}$, arterial oxygen tension $\left(\mathrm{PaO}_{2}\right)$ and $\mathrm{PaCO}_{2}$ were recorded whilst the patients were temporarily (2-3 $\mathrm{min}$ ) disconnected from the ventilator, breathing room air. Arterial blood gases from the radial artery were analysed using a blood gas analyser (ABL 500 Radiometer, Copenhagen, Denmark). During disconnection, the patients were continuously monitored for $\mathrm{SaO}_{2}$ and electrocardiographic pattern (ECG) and a physician was always in attendance. None of the patients showed a "dangerous response" to this practice (such as arrhythmia of loss of consciousness).

Serological data. These included serum sodium and potassium levels.

Nutritional status. Serum levels of protein, albumin, phosphate, blood urea and creatinine were measured. The percentage of ideal body weight was calculated from normal values according to height and age.

Pulmonary function test. These measurements were performed with the patients breathing spontaneously with supplemental $\mathrm{O}_{2}$ (to achieve an $\mathrm{SaO}_{2}>90 \%$ ) and the cuff of the endotracheal cannula inflated. After each set of manoeuvres (spirometry, maximal inspiratory pressure (MIP) and mouth occlusion pressure $\left(\mathrm{P}_{0.1}\right)$ ), the patients were briefly connected to the ventilator. Forced expiratory volume in one second $\left(\mathrm{FEV}_{1}\right)$ absolute value, $\mathrm{FEV}_{1}$ $\%$ predicted, and forced vital capacity (FVC) absolute and $\%$ predicted values were recorded using a Wright's spirometer connected to the endotracheal cannula. MIP against an occluded airway was recorded by a differential pressure transducer (Honeywell $\pm 300 \mathrm{cmH}_{2} \mathrm{O}$, Freeport, Illinois, USA), using a one-way valve with a tube-type piece with a small hole connected to the endotracheal cannula [19]. The manoeuvres were performed at residual volume; with this aim, the patients were encouraged to make a maximal exhalation and a short apnoea before the maximal inspiratory efforts. The MIP manoeuvres were performed a minimum of five times, with at least a 1 min interval between efforts, until two acceptable values, not differing from each other by more than $5 \%$, were obtained. The neuromuscular drive was measured, in 21 of the 42 patients, as the airway pressure, recorded with a transducer at the level of the endotracheal cannula, developed in the first $100 \mathrm{~ms}$ after the onset of a spontaneous inspiratory effort made after end-expiratory occlusion $\left(\mathrm{P}_{0.1}\right)$ [20]. The value of $\mathrm{P}_{0.1}$ was calculated as the mean of three measurements. Respiratory frequency $(f)$, tidal volume (VT) and the $f / \mathrm{V}_{\mathrm{T}}$ ratio (rapid shallow breathing index) were recorded during a period of $2 \mathrm{~min}$ using a heated pneumotachograph (Screenmate box 0586, Jaeger Gmbh, Hochberg, Germany) directly attached to the endotracheal cannula.

Number of pulmonary exacerbations. During the first 4 months of $\mathrm{MV}$, there was considered to be evidence of infection when a chest roentgenogram showed a pulmonary infiltrate and/or there was a sudden increase in white blood cell count, fever and increased production of sputum.
Evidence of cor pulmonale on ECG. Presence of one of the following three criteria was considered to be evidence of cor pulmonale: 1) "p-pulmonale"; 2) right ventricular hypertrophy; and 3) right axis deviation [21]. The numbers of previous pulmonary exacerbations and previous intubations were not taken into account for data analysis, since it was not always easy to collect reliable information for patients having been admitted to a variety of different hospitals during their life.

Information on survival was obtained either by telephone interview, or by direct observation if the patients were enrolled into the home care programme developed in our institution. Cause of death was not recorded outside the hospital. The study was completed in May 1992 to allow a 12 month minimum follow-up after intubation of the last patient entered into the study.

\section{Data analysis}

The Kaplan-Meier method was used to describe survival [22]. Survival rate was calculated setting the zero time 3 weeks after intubation, since this was the time elapsed to consider the weaning process difficult. Differences in survival between groups were assessed using the logrank test [22].

Statistical analysis to compare the difference between the "weaned" and "not weaned" group was performed with a rank test (Mann-Whitney) for nonparametric distributions of data. A p-value of less than 0.05 was considered significant.

The predictive models were developed using discriminant analysis. All of the previously described variables were tested in an attempt to establish differences between the weaned and not weaned group. Single predictor variable values were firstly computed, treating each variable as though it were the only predictor available. The predictor with the largest F-value was then chosen to enter the discriminant function. Successive steps added or deleted new predictors on the basis of their computed F-values conditioned on those already made part of the system. A matrix testing was then designed to assess the ability of this discriminant analysis to classify exactly, in a given group, a patient whose weaning success or lack of success and survival at $1 \mathrm{yr}$ was known by the follow-up study.

\section{Results}

During the study period, a total of 74 patients was admitted to our IICU after an episode of acute respiratory failure. All of the patients presented a difficult weaning process from MV. Five patients were affected by postsurgical complications, including diaphragmatic paralysis (2), cardiac disease (4), fibrothorax (5), pulmonary dystrophy (4), and neuromuscular diseases (3). Out of the 53 COPD patients, 3 died and 8 were successfully weaned during the first 3 weeks after intubation; therefore, only 42 patients were considered in the data analysis.

Table 2 shows the major characteristics of the whole COPD group when ventilated and clinically stable. Most 
Table 2. - Characteristics of COPD patients weaned (Group A) and not weaned (Group B) from MV and recorded while still on MV in a clinically stable phase

\begin{tabular}{|c|c|c|c|c|}
\hline Data & $\underset{n=23}{\text { Group } A}$ & $\begin{array}{c}\text { Group B } \\
n=19\end{array}$ & p-value & Total \\
\hline Age yrs & $67 \pm 8$ & $66 \pm 10$ & NS & $67 \pm 9$ \\
\hline Weight $\mathrm{kg}$ & $53.8 \pm 9.9$ & $55.2 \pm 6.5$ & NS & $54.7 \pm 7.9$ \\
\hline $\mathrm{PaO}_{2} \mathrm{kPa}$ & $6.8 \pm 1.0$ & $5.8 \pm 1.1$ & $<0.05$ & $6.3 \pm 1.1$ \\
\hline $\mathrm{PaCO}_{2} \mathrm{kPa}$ & $7.0 \pm 1.3$ & $9.1 \pm 2.4$ & $<0.01$ & $8.1 \pm 1.9$ \\
\hline $\mathrm{pH}$ & $7.39 \pm 0.05$ & $7.34 \pm 0.13$ & NS & $7.37 \pm 0.09$ \\
\hline $\mathrm{PaO}_{2} / \mathrm{FIO}_{2}$ on $\mathrm{MV}$ & $30.8 \pm 7.1$ & $26.9 \pm 7.0$ & NS & $28.7 \pm 7.0$ \\
\hline $\mathrm{PaCO}_{2} \mathrm{kPa}$ on $\mathrm{MV}$ & $6.9 \pm 1.5$ & $7.4 \pm 2.6$ & ns & $7.2 \pm 2.1$ \\
\hline $\mathrm{MIP} \mathrm{cmH}_{2} \mathrm{O}$ & $44.0 \pm 16.4$ & $31.3 \pm 6.1$ & $<0.05$ & $39.8 \pm 13.9$ \\
\hline $\mathrm{FEV}_{1} \%$ pred & $25 \pm 14$ & $21 \pm 7$ & NS & $23 \pm 12$ \\
\hline $\mathrm{FEV}_{1} / \mathrm{FVC} \%$ & $45 \pm 12$ & $40 \pm 9$ & NS & $43 \pm 10$ \\
\hline $\mathrm{P}_{0.1} \mathrm{cmH}_{2} \mathrm{O}$ & $3.5 \pm 1.3$ & $5.2 \pm 0.5$ & $<0.05$ & $4.1 \pm 1.2$ \\
\hline$f$ breaths $\cdot \min ^{-1}$ & $23.5 \pm 5.9$ & $26.4 \pm 3.8$ & NS & $24.8 \pm 5.2$ \\
\hline $\mathrm{VT}_{\mathrm{T}} l$ & $0.46 \pm 0.82$ & $0.40 \pm 0.99$ & NS & $0.44 \pm 0.94$ \\
\hline$f / \mathrm{V}_{\mathrm{T}} \quad \mathrm{b} \cdot \min ^{-1} / l$ & $55.2 \pm 16.6$ & $69.9 \pm 20.8$ & $<0.05$ & $61.5 \pm 19.5$ \\
\hline BW \% IBW & $87.9 \pm 11.9$ & $90.1 \pm 12.0$ & NS & $89.9 \pm 12.3$ \\
\hline Serum protein $\mathrm{g} \cdot \mathrm{l}^{-1}$ & $7.0 \pm 0.9$ & $6.5 \pm 0.7$ & NS & $6.7 \pm 0.8$ \\
\hline Serum albumin $\mathrm{g} \cdot l^{-1}$ & $3.3 \pm 0.5$ & $3.3 \pm 0.5$ & NS & $3.3 \pm 0.5$ \\
\hline Serum creatinine $\mathrm{mg} \cdot \mathrm{dl}^{-1}$ & $1.1 \pm 0.6$ & $1.0 \pm 0.3$ & NS & $1.0 \pm 0.4$ \\
\hline Creatinine/height & $0.7 \pm 0.2$ & $0.7 \pm 0.2$ & NS & $0.7 \pm 0.2$ \\
\hline Pulmonary exacerbations $\mathrm{n}$ & $1.2 \pm 1.1$ & $1.9 \pm 2.1$ & NS & $1.5 \pm 1.6$ \\
\hline Cor pulmonale on ECG \% & 46.7 & 49.0 & NS & 48.6 \\
\hline Duration of MV to weaning & $44.4 \pm 15.6$ & & NS & \\
\hline
\end{tabular}

Data are presented as mean \pm SD. Statistics between the groups were performed using the Mann-Whitney test. Characteristics of the whole group of $42 \mathrm{COPD}$ patients are given in the righthand column. $\mathrm{PaO}_{2}$ and $\mathrm{PaCO}_{2}$ : arterial oxygen and carbon dioxide tension, respectively; $\mathrm{FIO}_{2}$ : fractional inspiratory oxygen; MIP: maximal inspiratory pressure; $\mathrm{FEV}_{1}$ : forced expiratory volume in one second; $\%$ pred: percentage

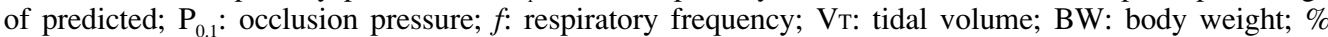
IBW: percentage ideal BW; NS: nonsignificant; COPD: chronic obstructive pulmonary disease; MV: mechanical ventilation.

of the patients were underweight, but the nutritional parameters were within the normal range in almost all of the patients. Arterial blood gases breathing room air were severely compromised, with mean $\pm \mathrm{SD} \mathrm{PaO}_{2} 6.3 \pm 1.1$ $\mathrm{kPa}$, and mean $\mathrm{PaCO}_{2} 8.1 \pm 1.9 \mathrm{kPa}$. More than half of the patients had a $\mathrm{FEV}_{1}$ less than $30 \%$ of predicted, and only two had a $\mathrm{FEV}_{1}$ more than $50 \%$ predicted. MIP was markedly reduced, and 29 patients did not achieve the pressure of $-50 \mathrm{cmH}_{2} \mathrm{O} . \mathrm{P}_{0.1}$ was elevated.

Of the 42 COPD patients requiring MV for more than 21 days, 23 were successfully weaned (Group A) and 19 were not (Group B). The duration of MV before admission to our IICU was $14.4 \pm 3.6$ days in Group A, and $13.1 \pm 2.9$ days in Group B. The length of MV from intubation to complete weaning in Group A was $44.4 \pm 15.6$ days (range 21-118 days). Group A patients did not require further $\mathrm{MV}$ during their remaining stay in the IICU, but two of them needed to be temporarily reventilated once in the following months, for an acute exacerbation of their disease. About half (13) of the Group A patients had the tracheostomy removed shortly after the successful weaning (range 5-20 days). As illustrated in table 2 for all the variables considered and in figure 1 for blood gases as individual data, the two groups were significantly different for blood gases breathing room air, MIP, and rapid shallow breathing index $\mathrm{P}_{0.1}$. Blood gases obtained during MV in PSV immediately before the spontaneous breathing trial, were not statistically different in the two groups. As expected, the degree of

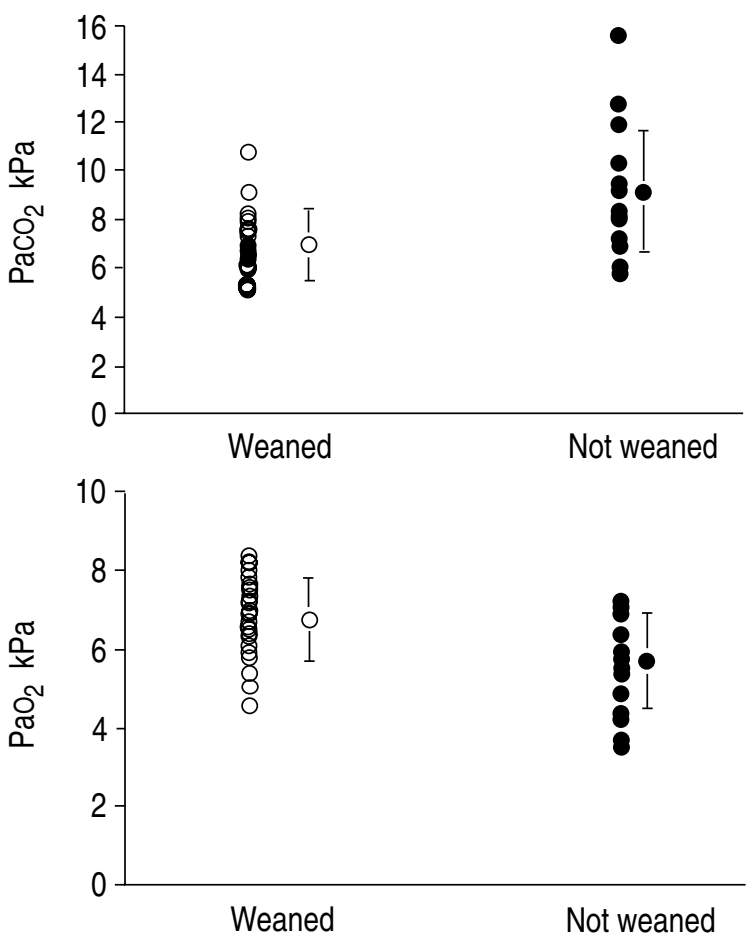

Fig. 1. - Arterial blood gases in the two groups of patients expressed as individual data and mean \pm SD. Measurements were performed in a clinically stable phase, whilst the patients were briefly $(2-3 \mathrm{~min})$ disconnected from the ventilator, breathing room air. $\mathrm{PaO}_{2}$ and $\mathrm{PaCO}_{2}$ : arterial oxygen and carbon dioxide tension, respectively. 
airway obstruction $\left(\mathrm{FEV}_{1}\right)$ was more severe in Group B, but not significantly so. Vital Capacity (VC) was also not statistically different. Nutritional parameters, anthropometric and serological data, ECG criteria for cor pulmonale and the number of acute pulmonary exacerbations were not significantly different between the two groups.

\section{Predictive factors for the weaning process}

The discriminant analysis showed that only six of the variables considered were important in allowing a distinction between patients that were successfully weaned or not. The sensitivity, specificity and predictive value of each of these parameters in discriminating the two groups of patients are illustrated in table 3 . After excluding $\mathrm{P}_{0.1}$, which was measured in only half of the patients, discriminant equations were designed, for the five remaining variables, able to correctly classify, in a given group, a patient whose successful or unsuccessful weaning was known by follow-up. In table 4 the predictive values of some discriminant equation are reported, employing the above-mentioned parameters. The best discriminant equation included $\mathrm{PaCO}_{2}$ and MIP, correctly predicting the outcome in $84 \%$ of the patients (table 5). In the subgroup of patients in which $\mathrm{P}_{0.1}$ was performed, the addition of the latter parameter to this discriminant equation increased the predictive value to $87 \%$.

\section{Survival of the COPD patients}

Survival data in the weaned (Group A), not weaned (Group B) and the whole group of COPD patients are shown in figure 2. At $2 \mathrm{yrs}, 68 \%$ of Group A patients and $22 \%$ of Group B were still alive $(p<0.01)$; the cumulative rate of survival was $40 \%$. Surviving Group $\mathrm{B}$ patients are currently ventilated at home, even if they still need frequent hospitalizations. Four patients from Group A and 10 from Group B died within the first 120 days after intubation. Two patients of Group A and 10 from Group B died in the hospital. The cause of death of these patients is reported in table 6. Mean follow-up of survival was 18 months.

Table 3. - Sensitivity, specificity and predictive value of some parameters in discriminating the weaned and not weaned patients

\begin{tabular}{|c|c|c|c|}
\hline Variables & $\begin{array}{c}\text { Sensitivity } \\
\%\end{array}$ & $\begin{array}{c}\text { Specificity } \\
\%\end{array}$ & $\begin{array}{c}\text { Predictive value } \\
\%\end{array}$ \\
\hline $\mathrm{PaCO}_{2} \mathrm{kPa}$ & 75 & 72 & 73 \\
\hline $\mathrm{PaO}_{2} \mathrm{kPa}$ & 79 & 72 & 77 \\
\hline $\mathrm{MIP} \mathrm{cmH}_{2} \mathrm{O}$ & 76 & 78 & 81 \\
\hline $\mathrm{P}_{01} \mathrm{cmH}_{2} \mathrm{O}^{*}$ & 78 & 90 & 84 \\
\hline$f / \mathrm{V}_{\mathrm{T}}$ breaths $\cdot \mathrm{min}^{-1} / l$ & 71 & 59 & 66 \\
\hline Serum protein $\mathrm{g} \cdot l^{-1}$ & 53 & 66 & 59 \\
\hline
\end{tabular}

*: recorded in only 21 patients. For abbreviations see legend to table 2 .
Table 4. - Predictive values of discriminant equations obtained employing some of the recorded variables

\begin{tabular}{lc}
\hline $\begin{array}{l}\text { Variables entered in } \\
\text { discriminant equation }\end{array}$ & $\begin{array}{c}\text { Predictive value } \\
\%\end{array}$ \\
\hline $\mathrm{PaCO}_{2}, \mathrm{MIP}$ & 84 \\
$\mathrm{PaO}_{2}, \mathrm{MIP}$ & 81 \\
$\mathrm{PaCO}_{2}, \mathrm{PaO}_{2}, \mathrm{MIP}$ & 81 \\
$\mathrm{PaCO}_{2}, \mathrm{PaO}_{2}, \mathrm{MIP}, f / \mathrm{VT}$ & 76 \\
$\mathrm{PaCO}_{2}, \mathrm{MIP}, \mathrm{VT}$ & 74 \\
$\mathrm{PaO}_{2}, \mathrm{PaCO}_{2}$ & 71 \\
\hline
\end{tabular}

For abbreviations see legend to table 2 .

Table 5. - Comparison between actual and predicted weaning success and failure using the best equation including $\mathrm{PaCO}_{2}$ and MIP

\begin{tabular}{|c|c|c|c|}
\hline & & \multicolumn{2}{|c|}{ Predicted } \\
\hline & & Succes & Failure \\
\hline \multirow[t]{2}{*}{ Actual } & Success & $89 \%$ & $11 \%$ \\
\hline & Failure & $19 \%$ & $81 \%$ \\
\hline \multicolumn{4}{|c|}{ Discriminant equation: } \\
\hline \multicolumn{3}{|c|}{$\begin{array}{l}\mathrm{Do}=-1.803+0.064 \mathrm{PaCO}_{2}-0.052 \mathrm{MIP} \\
\mathrm{r}=0.70 \quad \mathrm{p}<0.001\end{array}$} & 514 \\
\hline \multicolumn{4}{|c|}{ Predictive accuracy $=84 \%$} \\
\hline \multicolumn{4}{|c|}{ Sensitivity $=84 \%$} \\
\hline \multicolumn{4}{|c|}{ Specificity $=82 \%$} \\
\hline
\end{tabular}

For abbreviations see legend to table 2 .

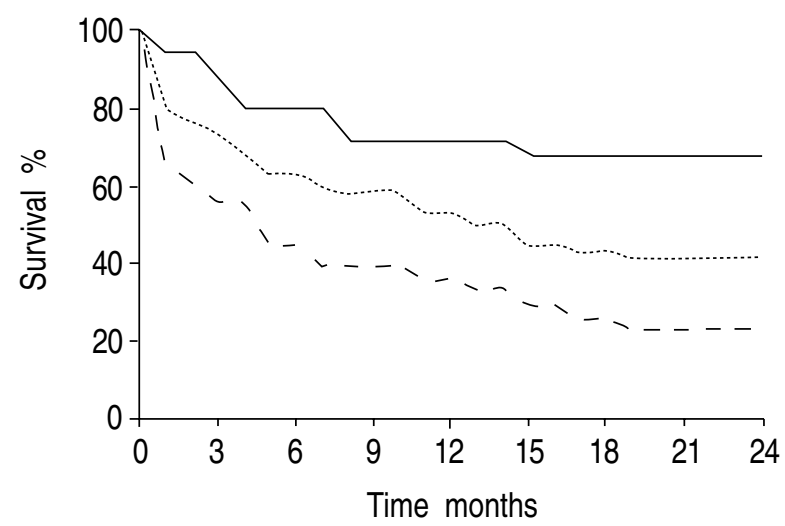

Fig. 2. - Life tables of the group of COPD patients as a whole and divided into those weaned and not weaned from MV. A statistically significant different was found starting from month 1 ( $\mathrm{p}<0.01, \log$ rank test) between the weaned and not weaned group.weaning; .................. : unsuccessful weaning; ................... : whole group. COPD: chronic obstructive pulmonary disease; MV: mechanical ventilation.

\section{Predictive factors for survival}

We employed discriminant analysis to identify the COPD patients destined to survive over one year. We were unable to find any significant equation able to predict the survival rate. The best equation including $\mathrm{PaCO}_{2}$, $\mathrm{PaO}_{2}$, age and serum protein level, could correctly predict the survival at one year in only $52 \%$ of the patients. 
Table 6. - Causes of death in the IICU

\begin{tabular}{lcccl}
\hline $\begin{array}{l}\text { Pat. } \\
\text { No. }\end{array}$ & Sex & Age & Group & \multicolumn{1}{c}{$\begin{array}{c}\text { Factor of } \\
\text { death }\end{array}$} \\
\hline 1 & M & 63 & A & $\begin{array}{l}\text { Pulmonary embolism } \\
2\end{array}$ \\
F & 61 & A & Suicide \\
3 & M & 52 & B & Sudden death \\
4 & M & 69 & B & MOFS \\
5 & M & 75 & B & Septic shock \\
6 & M & 78 & B & Myocardial infarction \\
7 & M & 62 & B & Pulmonary embolism \\
8 & M & 76 & B & Gastric bleeding \\
9 & M & 74 & B & Pulmonary embolism \\
10 & M & 67 & B & Sudden death \\
11 & M & 57 & B & MOFS \\
12 & M & 69 & B & MOFS \\
\hline
\end{tabular}

IICU: Intermediate Intensive Care Unit; MOFS: multiple organ failure syndrome; Pat: patient.

\section{Discussion}

This study shows that in a group of severe COPD patients with difficult weaning and prolonged MV: a) the survival rate is low when weaning is impossible in comparison to patients able to be weaned from $\mathrm{MV}$; b) there are no simple parameters to predict survival, although some indices may be helpful in predicting whether these patients will be eventually disconnected from MV or not.

The severity of functional impairment of our COPD was assessed in this study in stable condition, after the episode of acute exacerbation requiring MV. Although we did not know, due to the different origin of the patients, the values of respiratory function in the last stable situation prior to the intubation, we are confident that our patients were in advanced stages of the natural course of their disease. The patients in this study showed a severe airway obstruction, reduced $\mathrm{FEV}_{1} / \mathrm{FVC}$ index, together with compromised gas exchange. Arterial blood gas samples were withdrawn after 2-3 min of spontaneous breathing, a time probably not sufficient to reach a steady-state. However, it was considered dangerous (the patients were closely monitored during the trial) to wait longer in order to obtain a stable level. This standardized period of time, although brief, allowed for a comparison of the individual response to complete breathing autonomy. The same principle is applied for the recording of the ventilatory pattern after discontinuation from $\mathrm{MV}$, and is employed by several authors [23-25]. On the other hand, blood gases during MV were not different in the two groups; this may be due to the fact that artificial ventilation, in COPD patients, may improve nonhomogeneously distributed abnormalities, such as alveolar ventilation, ventilation/perfusion (V/Q) ratio, intrinsic positive end-expiratory pressure (PEEP), and time constant inequalities.

The prognosis of patients with advanced COPD is poor, with a mortality rate of about $50 \%$ at 3 yrs in patients who never required MV $[26,27]$. The survival of our patients at 2 yrs was about $40 \%$; the mortality was significantly higher in the not weaned group. In both groups, the mortality rate was mainly concentrated in the first
120 days. The immediate outcome of COPD requiring MV has been studied by several authors, survival ranging about 60 to $90 \%$ [2-9]. Survival at $1 \mathrm{yr}$ is variable, but nevertheless quite low (table 1). COPD patients undergoing prolonged (more than 21 days) MV have been less well studied; and, to our knowledge, this is the first report in Europe. The results of these studies are difficult to compare due to different severity of the disease, time, and modalities of MV. The total one year survival of our group was, however, higher than that in the study by MENZIES et al. [2], the functional status and time of ventilation being similar in the two studies. The cause of death and the quality of life after discharge were beyond the aim of this study. In patients who died in the hospital, however, no death occurred without a concomitant severe organ dysfunction; indeed no death could be considered to be related to complications of MV (e.g. pneumothorax).

Mechanical ventilation may be the last therapeutic resource in the natural history of patients with COPD. Unsuccessful discontinuation from $\mathrm{MV}$ is reported to occur in as many as $20 \%$ of patients affected by different disease [12], and may be even more pronounced in severe COPD. Diaphragmatic fatigue, high airway resistance, lung hyperinflation, hypoxaemia, hypercapnia, malnutrition and recurrent infections may be unfavourable events affecting the possibility of weaning $[13,14]$. On the other hand, prolonged MV with total or partial respiratory muscle unloading may lead to inspiratory muscle atrophy, further compromising the weaning process [28]. In our study, $54 \%$ of patients could be successfully weaned, in keeping with the results of Menzies et al. [2], whose weaned patients, however, showed a lesser degree of airway obstruction (stable state $\mathrm{FEV}_{1} 40 \%$ vs $25 \%$ of predicted in the present study). This difference in $\mathrm{FEV}_{1}$ may well be related to the fact that MENZIEs et al. [2] reported extubated, premorbid $\mathrm{FEV}_{1} \mathrm{~s}$, whilst the present study measured spirometry through a tracheostomy tube.

One of the factors influencing weaning may be the comprehensive programme of rehabilitation that the patients were submitted to. The availability of an IICU, as in our department, allows these programmes to be performed over an adequate period of time, as compared to general ICUs where prolonged bed occupation is usually impossible due to lack of beds [29].

Several indices have been proposed as predictive of outcome in attempting to wean a patient from MV. These have included vital capacity [23], maximal inspiratory pressure $[23,30]$ and minute ventilation $[23,24,31]$, the predictive powers of which have been considered very poor. Recently, rapid shallow breathing as assessed by $f / V_{T}$ ratio [25], CROP index (thoracic compliance, respiratory rate, arterial oxygenation and MIP) [25], the ratio inspiratory pressure/maximal inspiratory pressure [32], $\mathrm{P}_{0.1}$ [33], and other pooled measurements [2, 3] have been shown to be more accurate than the previous indices. Our patients were studied after a clinically stable state was reached, to avoid factors, such as e.g. fever, bronchospasm, increasing secretions, cardiovascular instability, lack of collaboration etc., influencing the 
reliability of the measurements. It is also important to note that both groups of patients were near $90 \%$ of ideal body weight and that serum albumin was normal; the predictive parameters were recorded after correction of any major nutritional dysfunction.

The ratio $f / \mathrm{V}_{\mathrm{T}}$ in Group B was higher than that of Group A, but was still within a range that was a common feature of weaned groups in other studies, performed in "acute" patients affected by different pathologies [25, 32]. Our results show that this index may not be useful in predicting weaning success or failure (see table 3 ) in ventilated COPD patients in a phase of clinical stability. This may depend on the inability of this group of patients to increase, during a short spontaneous breathing trial, the respiratory frequency (above $30-35$ breaths $\cdot \mathrm{min}^{-1}$ ) due to the impossibility of shortening the expiratory time, since they usually have severe airflow limitation and a high expiratory time-constant.

Among the other indices, $\mathrm{PaCO}_{2}$ and MIP could correctly predict weaning failure or success in about $85 \%$ of patients. Both an increase in $\mathrm{PaCO}_{2}$ and an impaired inspiratory muscle force may represent signs of respiratory pump insufficiency and of reduced alveolar ventilation, thought to be major causes of weaning failure.

Whilst we defined some simple parameters able to predict the weaning process, this was not possible for survival. Death during hospitalization, in fact, seldom seems to be linked to causes that prevent weaning (i.e. respiratory pump insufficiency) but to some other complication not necessarily dependent on MV (see table 6). Cause of death occurring outside our institution, as well as daily living activity, could not be considered in our analysis, since information obtained by telephone was not always sufficiently precise.

It is important to note that the predictive factors and models developed in this study are not yet validated and, therefore, will require further prospective studies. The validation of predictive indices of weaning success or failure may contribute to the decision of whether or not these patients should eventually enter a programme of home ventilation.

This study demonstrated that COPD patients with prolonged mechanical ventilation may often be successfully weaned in Intermediate Intensive Care Units, where the rehabilitation programme can be continued for a longer time than in a standard ICU. The total survival rate at 2 yrs is about $60 \%$, but is very poor in the subgroup of patients not able to be weaned. Indeed, a simple equation, considering $\mathrm{PaCO}_{2}$ and MIP recorded in a clinically stable state may predict, after being prospectively validated, the weaning success or failure, but not the survival rate.

Acknowledgements: The authors wish to thank all the nurses of their department for their enthusiastic and skilful work and R.C. Stennert for kindly reviewing the English of the manuscript.

\section{References}

1. Rochester DF, Martin LL. Respiratory muscle rest. In: Roussos C, Macklem PT, eds. The Thorax. New York, Dekker, 1985; Part I (43): pp. 1303-1328.
2. Menzies R, Gibbons W, Goldberg P. Determinants of weaning and survival among patients with COPD who require mechanical ventilation for acute respiratory failure. Chest 1989; 95: 398-405.

3. Kaelin R, Assimacopoulos A, Chevrolet JC. Failure to predict six month survival of patients with COPD requiring mechanical ventilation by analysis of simple indices. A prospective study. Chest 1987; 92: 971-978.

4. Gracey DR, Naessens JM, Krishan I, Marsh M. Hospital and posthospital survival in patients mechanicallyventilated for more than 29 days. Chest 1992; 101: 211214.

5. Potgieter PD, Rosenthal E, Benatar SR. Immediate and long-term survival in patients admitted to a respiratory ICU. Crit Care Med 1985; 13: 798-802.

6. Petheram IS, Branthwaite MA. Mechanical ventilation for pulmonary disease. A six year survey. Anaesthesia 1980; 35: 467-473.

7. Spicher JE, White DP. Outcome and function following prolonged mechanical ventilation. Arch Intern Med 1987; 147: 421-425.

8. Nunn JF, Milledge JS, Singaraya J. Survival of patients ventilated in an intensive therapy unit. Br Med J 1979; 1: $1525-1527$.

9. Gillespie DJ, Marsh HMM, Divertie MB, Meadows JA. Clinical outcome of respiratory failure in patients requiring prolonged ( $>24$ hours) mechanical ventilation. Chest 1986; 90: 364-369.

10. Bradley RD, Spencer GT, Semple SJG. Tracheostomy and artificial ventilation in the treatment of acute exacerbations of chronic lung disease. Lancet 1964; i: 854-859.

11. Jessen O, Kristensen HS, Rasmussen K. Tracheostomy and artificial ventilation in chronic lung disease. Lancet 1967; ii: 9-12.

12. Tahvanainen J, Salmenpera M, Nikki P. Extubation criteria after weaning from intermittent mandatory ventilation and continuous positive airway pressure. Crit Care Med 1983; 11: 702-707.

13. Pourriat JL, Lamberto Ch, Hoang $\mathrm{Ph}$, Fournier JL, Vasseur B. Diaphragmatic fatigue and breathing pattern during weaning from mechanical ventilation in COPD patients. Chest 1986; 90: 703-707.

14. Roussos Ch. Respiratory muscle fatigue in the hypercapnic patient. Bull Eur Physiopathol Respir 1979; 15: $117-123$.

15. Heffner JE. Timing of tracheotomy in mechanicallyventilated patients. Am Rev Respir Dis 1993; 147: 768-771.

16. American Thoracic Society. Standards for the diagnosis and care of patients with chronic obstructive pulmonary disease (COPD) and asthma. Am Rev Respir Dis 1987; 136: 225-243.

17. Rochester DF. Tests of respiratory muscle function. Clin Chest Med 1988; 9: 249-261.

18. Aldrich TK, Uhrlass RM. Weaning from mechanical ventilation: successful use of modified inspiratory resistive training in muscular dystrophy. Crit Care Med 1987; 15: 427-429.

19. Black L, Hyatt R. Maximal airway pressures: normal values and relationship to age and sex. Am Rev Respir Dis 1969; 99: 696-702.

20. Withelaw WA, Derenne JP, Milic-Emili J. Occlusion pressure as a measure of respiratory center output in conscious man. Respir Physiol 1975; 23: 181-199.

21. Marriott HJL. In: Practical Electrocardiography. 7th edn. Baltimore, Williams and Wilkins, 1983. 
22. Peto R, Pike MC, Armitage P, et al. Design and analysis of randomized clinical trials requiring prolonged observation in each patient: analysis and examples. $B r J$ Cancer 1977; 35: 1-39.

23. Sahn SA, Lakshminarayan S. Beside criteria for discontinuation of mechanical ventilation. Chest 1973; 63: 1002-1005.

24. Stetson JB. Introductory essay. Int Anesthesiol Clin 1970; 8: 767-779.

25. Yang KL, Tobin M. A prospective study of indexes predicting the outcome of trials of weaning from mechanical ventilation. N Engl J Med 1991; 324: 1445-1450.

26. Anthonisen NR. Prognosis in chronic obstructive pulmonary disease: results from multicenter clinical trials. $\mathrm{Am}$ Rev Respir Dis 1989; 140: S95-S99.

27. Burrows B, Bloom JW, Traver GA, Cline MO. The course and prognosis of different forms of chronic airways obstruction in a sample from the general population. $N$ Engl J Med 1987; 31: 1309-1314.
28. Marini JJ. Exertion during ventilatory support: how much and how important? Respir Care 1986; 31: 385387.

29. Elpern EH, Silver MR, Rosen RL, Bone RC. The noninvasive respiratory care unit. Patterns of use and financial implications. Chest 1991; 99: 205-208.

30. Feeley TW, Hedley-Whyte J. Weaning from controlled ventilation and supplemental oxygen. $N$ Engl J Med 1975; 292: 303-306.

31. Pierson DJ. Weaning from mechanical ventilation in acute respiratory failure: concepts, indications and techniques. Respir Care 1983; 28: 646-662.

32. Yang KL. Inspiratory pressure/maximal inspiratory pressure ratio: a predictive index of weaning outcome. Intens Care Med 1993; 19: 204-208.

33. Montgomery AB, Holle RHO, Neagley SR, Pierson DJ, Schoene RB. Prediction of successful ventilator weaning using airway occlusion pressure and hypercapnic challenge. Chest 1991; 4: 496-499. 